\title{
AL SERVICIO DEL REY. SOBRE LA CARTA REAL DIPLOMÁTICA DE LA CORONA DE ARAGÓN (1336-1458**
}

\author{
IN THE SERVICE OF THE KING. CONCERNING ROYAL \\ DIPLOMATIC LETTERS IN THE CROWN OF ARAGON (1336-1458)
}

\author{
MARÍA LUZ MANDINGORRA LLAVATA \\ Universitat de València \\ http://orcid.org/0000-0001-7263-4043
}

\begin{abstract}
Resumen: El objetivo de este artículo es reconstruir la evolución morfológica de la carta real diplomática catalanoaragonesa entre los reinados de Pedro el Ceremonioso y Alfonso el Magnánimo. A lo largo de este período, esta tipología documental, siguiendo los principios del Ars dictaminis, adaptó sus características externas e internas a las acciones jurídicas que contenía y a sus destinatarios, sin renunciar por ello a su simplicidad material y textual. Con su adecuación a las necesidades comunicativas de la monarquía, la carta real diplomática se convirtió en un instrumento de gobierno que contribuyó al fortalecimiento del poder real y anticipó formas que alcanzarán su pleno desarrollo en época moderna.
\end{abstract}

Palabras clave: diplomática; carta real; Cancillería; Corona de Aragón; Baja Edad Media.

\begin{abstract}
The aim of this paper is to reconstruct the morphological evolution of the royal diplomatic letter in the Crown of Aragon between the reigns of Peter the Ceremonious and Alfonso the Magnanimous. During this period, the form taken by this document was adapted to its contents and those in receipt of it, according to the principles of the Ars dictaminis, without relinquishing its material and textual simplicity in the process. With its adaptation to the communicative requirements of the monarchy, the royal diplomatic letter became an instrument of governance that helped to strengthen royal power and anticipated mechanisms that would be fully developed during the Early Modern Period.
\end{abstract}

Keywords: diplomacy; royal diplomatic letter; Chancery; Crown of Aragon; Middle Ages.

* Esta investigación se enmarca en el Proyecto de investigación financiado Documentación real de la Edad Media conservada en archivos valencianos: Edición crítica y estudio del Ministerio de Economía y Competitividad. Secretaría de Estado de Investigación, Desarrollo e Innovación de España. Proyecto HAR2012-36656. 


\section{SUMARIO}

1. La carta real diplomática catalanoaragonesa.- 2. Lletres patents y lletres closes.- 3. La evolución de la carta real diplomática.- 3.1. La suscripción autógrafa del rey.- 3.2. La definición de la carta cerrada y la introducción de las lenguas vulgares.- 3.3. La especialización de la carta cerrada y las variantes en la carta abierta.3.4. El triunfo de la suscripción regia y del sello secreto.- 4. Conclusión.- 5. Bibliografía citada.

\section{LA CARTA REAL DIPLOMÁTICA CATALANOARAGONESA ${ }^{1}$}

Nós, estants en Barcelona, trametem lletres a tots e sengles prelats, comtes, barons, ciutats e viles, generalment tothom, de qual estament fos-se, feuater o aloer, que ens venguessen acórrer en Cerdanya, on anàvem per cobrar la vila de Puigcerdà ${ }^{2}$

Esta llamada de Pedro IV a sus súbditos el 22 de noviembre de 1344, en un momento de acuciante necesidad, pudo llevarse a cabo porque disponía de un instrumento comunicativo eficaz a tal efecto, la carta. Eficaz, de un lado, por su austera materialidad, bien diferenciada del privilegio: uso del papel en lugar del pergamino, ausencia del signo real y aposición de un sello de placa, tal como estipulaban las Ordinacions de la Casa i Cort ${ }^{3}$. De otro, por su génesis, que se simplificaba al máximo si partía de una orden directa del rey -habitualmente al secretario- y su validación se realizaba por medio de la suscripción autógrafa del soberano y del sello secreto, custodiado por el primer camarlengo. Así mismo, este procedimiento permitía un control absoluto del monarca sobre su elaboración, dado que tanto camarlengos como secretarios eran personas de su absoluta confianza ${ }^{4}$. En este sentido, se puede afirmar que, desde el punto de vista de la diplomática, la carta real catalanoaragonesa

\footnotetext{
${ }^{1}$ Abreviaturas utilizadas: ACA = Archivo de la Corona de Aragón; ACB = Archivo Capitular de Barcelona; ACC = Archivio Comunale di Cagliari; ACV = Archivo de la Catedral de Valencia; AHCG = Arxiu Històric de la Ciutat de Girona; ARV = Archivo del Reino de Valencia; Canc.$=$ Cancillería; C.r. $=$ Cartas reales; Ll.r. $=$ Lletres reials; Reg. $=$ Registro; s.d. $=$ sin data; s.l. = sin lugar.

${ }^{2}$ Pere el Cerimoniós 1983,p. 1087.

${ }^{3}$ En la rúbrica "De la manera de sagellar ab segells de cera e ab bulla"; $c f$. Pere el Cerimoniós 2009 , p. 196. El uso del papel en la carta se introduce en época de Jaime I; $c f$. Aragó, Trenchs 1979, p. 358. Para la calidad del papel utilizado en las cartas véase Arnall, Gironella 2000, p. 32.

${ }^{4}$ Sobre los camarlengos, véase la rúbrica de las Ordinacions "Ací comença la segona part del libre, e primerament de l'offici dels camarlenchs"; $c f$. Pere el Cerimoniós 2009, p. 89. Para los secretarios, véase "Dels escrivans secretaris", $c f$. ibidem, p. 99. Acerca del sello secreto y su custodia por el camarlengo, véanse además Finke 1908-1922, vol. I, p. L; Sagarra 1916-1932, vol. I, p. 55. La conservación separada del sello secreto podría explicar por qué no se pudo encontrar el del infante Juan cuando, en 1357, Pedro el Ceremonioso ordenó enviar a su esposa,
} 
había comenzado a sustraerse a las reglas que hasta ese momento habían regido el documento medieval para convertirse en un instrumento de gobierno moderno 5 .

Partiendo de esta premisa, nos proponemos analizar la evolución morfológica de la carta real diplomática de la Corona de Aragón entre los reinados de Pedro el Ceremonioso y Alfonso el Magnánimo. Esta acotación viene determinada, en primer lugar, porque el reinado de Pedro IV marca el inicio de un proceso que condujo a la renovación de este tipo documental ${ }^{6}$ y a su conversión en un producto dominante en la Cancillería 7 . A lo largo de este período, además, a partir del modelo inicial, la carta se dotó de rasgos diferenciadores que le permitieron adecuarse tanto a su contenido jurídico como a su destinatario. Y lo hizo por medio de su formato abierto o cerrado (lletra patent y lletra closa $^{8}$ ), de su selección linguística y, sobre todo, de una estructura textual flexible que posibilitó la introducción de elementos destinados a conferirle una mayor solemnidad o, por el contrario, su exclusión, con el fin de agilizar su expedición. Nuestro objetivo es, por consiguiente, analizar las transformaciones de la carta en sus características internas y externas; no pretendemos reconstruir los procesos de génesis documental ${ }^{9}$, ya que ello excedería las posibilidades de estas páginas, ni efectuar un estudio de carácter institucional, dado que existe una prolífica tradición investigadora sobre la Cancillería, que se ha centrado, precisamente, en la identificación de su personal y en el análisis de su funcionamiento ${ }^{10}$.

La investigación sobre un tipo documental requiere la valoración de un número importante de originales, los únicos que nos pueden informar plenamente acerca de su materialidad. Con todo, el ingente volumen de cartas conservadas ${ }^{11}$ obligaba a trabajar sobre una muestra que resultara representativa. Por ello, para la realización de este estudio se han analizado las

Leonor de Sicilia, los sellos del duque de Gerona; ACA, Canc., Reg. 1152, f. 198v, $c f$. Sagarra 1916-1932, vol. I, p. 166.

${ }^{5}$ Véase Gimeno 1999, pp. 195 y ss.

${ }^{6}$ Cf. Conde, Cárcel 1996, pp. 287-288; Arnall, Gironella 2000, vol. I, p. 27.

${ }^{7}$ Cf. Trenchs, Aragó 1983, p. 14; Casula 1973, pp. 106-107.

${ }^{8}$ Denominaciones que responden tanto a las propias nomenclaturas de la época, como a la bibliografía sobre la producción documental en la Corona de Aragón; $c f$. Arnall, Gironella 2000, vol. I, pp. 20-161; Conde, Cárcel 1996, p. 286; Oliva, Schena 2012, vol. I, pp. IX-LXV; véanse también Casula 1970, 1977; D’Arienzo 1970.

${ }^{9}$ Sobre este asunto véanse Sevillano 1950, pp. 200-204; 1968, pp. 28-30; Oliva, Schena 2012, pp. XXI-XXVI; Trenchs, Aragó 1983, pp. 83-99. Véanse también Finke 1908-1922; Péquignot 2009.

${ }^{10}$ Véanse, por ejemplo, Aragó 1973; Casula 1967, 1979; Canellas, Trenchs 1988; Collura 1983; D’Arienzo 1974a, 1974b, 1981; Sevillano 1950, 1965, 1968; Trenchs, Aragó 1983, Trenchs 1991.

${ }^{11}$ Cf. Trenchs, Aragó 1983, p. 14. 
1027 cartas reales originales que custodia el ARV ${ }^{12}$ para el período objeto de estudio. Aunque se trata de una colección facticia, incluye una gran variedad de acciones jurídicas, ya que, además de mandatos, también aparecen provisiones, encargos, concesiones, reconocimientos, exenciones e, incluso, ruegos y agradecimientos. Así mismo, con el fin de ampliar y diversificar la base de la investigación, se han utilizado también los fondos del $\mathrm{ACV}^{13}$, una selección de cartas y registros del $\mathrm{ACA}^{14}$, así como algunas ediciones de cartas reales disponibles en la actualidad ${ }^{15}$.

\section{LLETRES PATENTS Y LLETRES CLOSES}

Hasta los años centrales del siglo XIV la carta real diplomática constituía un producto sustancialmente unitario carente de variantes significativas. Se presentaba preferentemente en forma abierta y, cuando adoptaba el formato cerrado, no mostraba más diferencia que la aposición del sello, habitualmente el común, que aparecía sobre el cierre y no en el centro del reverso como era propio de la carta abierta. Además, ambas eran redactadas mayoritariamente en lengua latina ${ }^{16} \mathrm{y}$, con independencia de la acción jurídica que contenían, seguían la misma estructura diplomática, ya definida durante el reinado de Jaime $\mathrm{I}^{17}$. El protocolo contaba con la intitulación completa del monarca, seguida de la dirección y la salutación; el texto se limitaba a la narración y la disposición, y en el escatocolo figuraban la datación y la suscripción de un funcionario de la Cancillería. Este esquema se mantendrá vigente para algunas acciones jurídicas, como por ejemplo el mandato, durante todo el período objeto

${ }^{12}$ Arxiu 2000, p. 20.

${ }^{13}$ Conserva 76 cartas originales para el período estudiado.

${ }^{14}$ Un total de 300 cartas de Martín I -correspondientes a los años 1398-1399, 1405 y 14081410 - y 500 del reinado de Alfonso V, entre las que se incluyen cartas de su esposa, la reina María. Así mismo se han consultado diversos registros de los reinados de Pedro IV (Curie, Exercitum et curiarum, Graciarum, Guerre sarracenorum, Maioricarum, Peccunie y Sigilli Secreti) y de Alfonso V (Comune, Curie, Diversorum y Secretorum).

${ }^{15}$ En concreto, Arnall, Gironella 2000; Casula 1970, 1977; D'Arienzo 1970; Gubern 1955; Oliva, Schena 2012; Oliveras 1946; Rodrigo, Riera 2013; Rubió i Lluch 1908-1921; Sánchez 1967; Vincke 1936. Las tablas se han elaborado sobre la base de las cartas del ARV, la colección completa de originales más amplia que se ha analizado. Naturalmente, su función no es ofrecer cifras con valor absoluto, sino mostrar tendencias de comportamiento.

${ }^{16}$ Basta con revisar Finke 1908-1922 y Vincke 1936, aunque los memoriales que incluían las cartas se redactaban frecuentemente en vulgar, como se advierte, por ejemplo, en el enviado por Jaime II a los reyes Fernando IV y María de Castilla en 1295 (ACA, Canc., Reg. 252, f. 26r-v) o el remitido por Alfonso IV a Federico III de Sicilia en 1328 (ACA, Canc., Reg. 562, ff. 40r-43v), $c f$. Rodrigo, Riera 2013, vol. I, núm. 13, pp. 102-103 y núm. 269, pp. 303-306 respectivamente.

${ }^{17}$ Cf. Aragó, Trenchs 1979, p. 358. 
de análisis. La única excepción se produce en aquellas cartas en las que se efectúan concesiones o que suponen algún tipo de gracia o admisión por parte del rey, como son las absoluciones, exenciones o reconocimientos de deuda. En estos casos, el dominio de la carta abierta es absoluto y el tenor ofrece algunos elementos distintivos como la introducción del "Nos" mayestático en la intitulación, la ausencia de salutación y, desde época de Alfonso el Benigno, la corroboración ${ }^{18}$. También hallamos, naturalmente, variaciones en aquellas cartas en las que el destinatario se antepone al emisor, de acuerdo con el vínculo existente entre ambos. Así se produce, por ejemplo, en las enviadas al papa, como esta de Jaime II: Reverentissimo ac sanctissimo in Christo patri ac domino Clementi, divina providencia sacrosancte Romane ac universalis ecclesie summo pontifici, Iacobus, Dei gracia rex Aragonum, etc. ${ }^{19}$.

No podemos olvidar a este respecto que el desarrollo del Ars dictamini $^{20}$ había hecho de la carta un dispositivo al servicio de las instancias del poder y, para ello, la había adaptado al peculiar significado que el hecho documental asumía en la sociedad de la Edad Media ${ }^{21}$, ya que, como afirma Petrucci, además de relaciones jurídicas o administrativas, el documento también expresaba conceptos políticos o creencias religiosas por medio de un complejo entramado de fórmulas, citas y artificios textuales y formales ${ }^{22}$. Con este fin, el arte epistolar medieval abandonó el eje central de la retórica clásica, la persuasión, para centrarse en la naturaleza del vínculo autordestinatario ${ }^{23}$. De este modo, la carta se convirtió en una auténtica retórica de la relación personal ${ }^{24} \mathrm{y}$, con las Rationes dictandi de Bolonia, adoptaría un esquema ${ }^{25}$ integrado por la salutatio -intitulación, inscripción y salutación-, a la que sigue la narratio -la narración- previa a la petitio -la disposición-, para finalizar con la conclusio, en la que se exponen las consecuencias de la realización o no del asunto objeto de la carta ${ }^{26}$.

\footnotetext{
${ }^{18}$ Véanse, por ejemplo, AHCG, Ll.r. núm. 39 [1330, febrero 23. Tarragona] y núm. 66 [1333, agosto 21. Montblanc], $c f$. Arnall, Gironella 2000, vol. I, pp. 240-241 y 268-269 respectivamente.

${ }^{19}$ ACA, Canc., Reg. 335, f. 333 [1309, enero 17. Huesca], cf. Vincke 1936, núm. 140, pp. 86-87.

${ }^{20} \mathrm{La}$ influencia del Ars dictaminis en la prosa cancilleresca ha sido estudiada, entre otros, por Olivar 1936; Rubió i Balaguer 1990; Ruiz Calonja 1956. Véase también Arnall, Gironella 2000, vol. I, pp. 165-202.

${ }^{21} C f$. Murphy 1986, p. 215.

${ }^{22}$ Cf. Petrucci 1963, p. 796.

${ }^{23}$ Cf. Perelman 1991, p. 103.

${ }^{24}$ Cf. ibidem, p. 107.

${ }^{25} \mathrm{Cf}$. Murphy 1986, p. 231.

${ }^{26} C f$. Rockinger 1863-1864, pp. 10-11. Según Murphy, las Rationes dictandi, hoy consideradas anónimas, fueron erróneamente atribuidas por Rockinger a Alberico de Montecassino; cf. Murphy 1986, p. 228.
} 
De acuerdo con estas exigencias, la formalidad de la carta real diplomática catalanoaragonesa no es en modo alguno arbitraria, sino que es consecuencia de la decidida intención del emisor, del monarca, de efectuar una puesta en escena de su poder ${ }^{27}$ con una precisa identificación de las relaciones jerárquicas que mantiene con los destinatarios ${ }^{28}$. En ese sentido, los resultados de esta investigación ponen de manifiesto tres hechos clave:

1. A lo largo del período estudiado domina la forma de la carta abierta, redactada en latín, aunque crece paulatinamente el uso de la lengua vulgar.

2. No obstante, la carta abierta dista mucho de presentar unas características extrínsecas e intrínsecas uniformes, sino que adapta su morfología, incluida la selección linguiística, tanto a las acciones jurídicas a las que da cabida como a la condición o identidad del destinatario. Por ello, las cartas que dan soporte a acciones como el mandato, que son expresión de la autoridad real, se hallan desprovistas de elementos específicos de solemnidad. Sin embargo, la concesión, que es el resultado de la generosidad del rey, se presenta en forma de carta abierta dotada de elementos de aparato, como son la incorporación del pronombre "Nos" en la intitulación, la ausencia de salutación y la inclusión de la corroboración, cláusula presente en los privilegios, a los que este modelo de carta se aproxima aún más mediante el uso del latín.

3. Por último, la carta cerrada, redactada de modo mayoritario en lengua vulgar, con el protocolo reducido a una intitulación y una dirección breves y carente de saludo, era el instrumento del secreto y la privacidad ${ }^{29}$. Por ese motivo, no se utilizaba prácticamente nunca para acciones jurídicas que comportaran algún tipo de concesión real. En cambio, constituía un vehículo habitual para los mandatos y también, como veremos, para los ruegos y los

\footnotetext{
${ }^{27}$ Un excelente testimonio sensu contrario nos lo ofrece la "carta disimulada" enviada en 1338 por Pedro IV a Bernat de Cancerch, alcaide de los cristianos residentes en Marruecos, que carece de intitulación, inscripción, salutación y corroboración y fue redactada "sub hac forma, ne videatur mitti ex parte regis"; ACA, Canc., Reg. 1111, f. 64r-v, $c f$. Rodrigo, Riera 2013, núm. 367, vol. I, p. 11.

${ }^{28}$ Así se regula en la rúbrica de las Ordinacions "De la manera d'escriure letres a diverses persones"; $c f$. Pere el Cerimoniós 2009, p. 182 y en las rúbricas "Con se deu scriure a diverses persones segons grau de cascun e primerament qui en les letres deuen ésser preposats" "De la manera de scriure als cardenals" y "De la manera de l'escriure a aquelles persones les quals són postposades a Nós en les letres", que ofrecen el elenco de modelos necesarios para formular la inscripción y la salutación; cf. ibidem 2009, pp. 183-194.

${ }^{29}$ Cf. Conde, Cárcel 1996, pp. 286 y ss.; Arnall, Gironella 2000, vol. I, p. 24. Constituye un buen ejemplo la carta que Pedro IV envió en 1376 al abad de Roda conminándole a que dejara la abadía por su vergonzoso comportamiento y amenazándole con hacerlo público si no obedecía sus órdenes; ACA, Canc., Reg. 1251, f. 10v, $c f$. Vincke 1936, núm. 603, pp. 509-510.
} 
agradecimientos, ya que, además de garantizar una comunicación segura ${ }^{30}$, permitía ocultar lo que podrían ser considerados rasgos de "debilidad" del monarca $^{31}$.

\section{LA EVOLUCIÓN DE LA CARTA REAL DIPLOMÁTICA}

¿De qué modo se define en el tiempo esta adecuación de las cartas a las distintas acciones jurídicas, a las diferentes intenciones del autor, a la diversidad de los destinatarios?

Como ya se ha dicho, será durante el reinado de Pedro IV $^{32}$ cuando se asista al fin de la unidad morfológica de la carta, a través de una serie de fenómenos que harán de ella un tipo documental nuevo, perfectamente adaptado a las necesidades comunicativas de la monarquía. Entre ellos destaca la introducción de la firma del rey, que marca un punto de inflexión en la producción documental de la Cancillería de la Corona de Aragón, ya que con ella da comienzo una participación directa del soberano en la génesis del documento, que continuará mediante la introducción de anotaciones fuera del tenor documental e, incluso, con la redacción autógrafa de algunas cartas. Este hecho se halla en conexión con la definición de una formalidad específica para la carta cerrada, que incluirá el uso predominante de la lengua vulgar, y con el inicio de un proceso de especialización que culminará durante el reinado de Alfonso el Magnánimo.

\subsection{La suscripción autógrafa del rey}

Evidentemente, la suscripción autógrafa del rey aportaba a la carta una solemnidad de la que carecía la suscripción de un oficial de la Cancillería y resultaba equiparable al signum regis presente en los privilegios. Ahora bien, a diferencia de este, la firma manifiesta un compromiso personal del soberano con el destinatario, garantiza la existencia de un vínculo directo entre ambos, tanto para la expresión de un mandato, como para la concesión de una merced.

\footnotetext{
${ }^{30}$ Es el caso de las cartas cerradas dirigidas por Pedro IV al Consell de la ciudad de Valencia durante la guerra con Castilla, véase Sánchez 1967.

${ }^{31}$ No es casual que se expidieran en formato cerrado las excusas presentadas por el rey Pedro IV a Bertran du Guesclin en 1374 por el retraso en el pago de las cantidades que le debía; ACA, Canc., Reg. 1091, ff. 80v-81r, $c f$. Rodrigo, Riera 2013, núm. 638, vol. II, pp. 710-711.

${ }^{32}$ Sin pretensión de efectuar un análisis comparativo, cabe recordar que Arthur Giry señaló la subida de Felipe VI de Valois al trono de Francia en 1328 como el "point de départ d'une nouvelle période diplomatique"; $c f$. Giry 1894, p. 765.
} 
Es muy significativo que la carta más antigua que presenta la firma del rey, dirigida en 1339 al conde de Terranova solicitándole el traslado de la condesa a la corte, vaya acompañada de una apostilla autógrafa: Rogamos vos que lueg[o] nos enviedes la contessa segunt que desuso es dito. Sobre aquesto creet $a \cdot N$ Berenguer de Codinachs ${ }^{33}$. Del mismo modo, resulta muy revelador el cuidado con el que los monarcas justificaban la ausencia de su firma, sobre todo, a medida que crecía su utilización (véase tabla 1). Así se advierte en cartas de la etapa final del reinado de Fernando I, que cuentan con la suscripción autógrafa de su hijo, Alfonsus primogenitus, explicada puntualmente con la frase: E per indisposició de nostra persona, de mà de nostre primogènit signada $^{34}$ (véase fig. 1), o en cartas de la reina María, esposa de Alfonso el Magnánimo: Et propter indisposicionem persone nostre, signata manu regii ac nostri Cancellarii ${ }^{35}$.

\begin{tabular}{|c|c|c|c|c|}
\hline REINADO & $\begin{array}{c}\text { CARTAS } \\
\text { ABIERTAS }\end{array}$ & $\begin{array}{c}\text { CARTAS ABIERTAS } \\
\text { CON FIRMA }\end{array}$ & $\begin{array}{c}\text { CARTAS } \\
\text { CERRADAS }\end{array}$ & $\begin{array}{c}\text { CARTAS } \\
\text { CERRADAS } \\
\text { CON FIRMA }\end{array}$ \\
\hline PEDRO IV & 63 & 27 & 2 & 2 \\
\hline JUAN I & 33 & 20 & 4 & 3 \\
\hline MARTÍN I & 78 & 54 & 10 & 9 \\
\hline FERNANDO I & 28 & 25 & 6 & 6 \\
\hline MARÍA & 77 & 69 & 47 & 47 \\
\hline ALFONSO V & 598 & 590 & 78 & 78 \\
\hline
\end{tabular}

Tabla 1. Presencia de la suscripción autógrafa de los monarcas en las cartas reales del ARV.

${ }^{33}$ ACA, Canc., Reg. 1113, f. 5v. En relación con el mismo asunto, el 22 de julio el rey envió a la condesa, Margarita de Lauria, otra carta, también firmada de modo autógrafo y en la que escribió: "Rogamos vos que, vistas las presentes, vengades a Nos, segunt que es dito desuso e sobre aquesto creet a'N Berenguer de Codinachs" (f. 7r). Finalmente, el 7 de agosto le remitió otra carta que apostilló como sigue: "Rogamos vos que luego vengades e desto no us escusedes. Scripta de nuestra mano" (f. 11v).

${ }^{34}$ ARV, C.r. Fernando I núm. 22 a 33, todas ellas dadas entre el 21 de agosto de 1415 y el 15 de febrero de 1416.

${ }^{35}$ ARV, C.r. María reina núm. 84 y 85 [1435, mayo 7. Valencia]. 


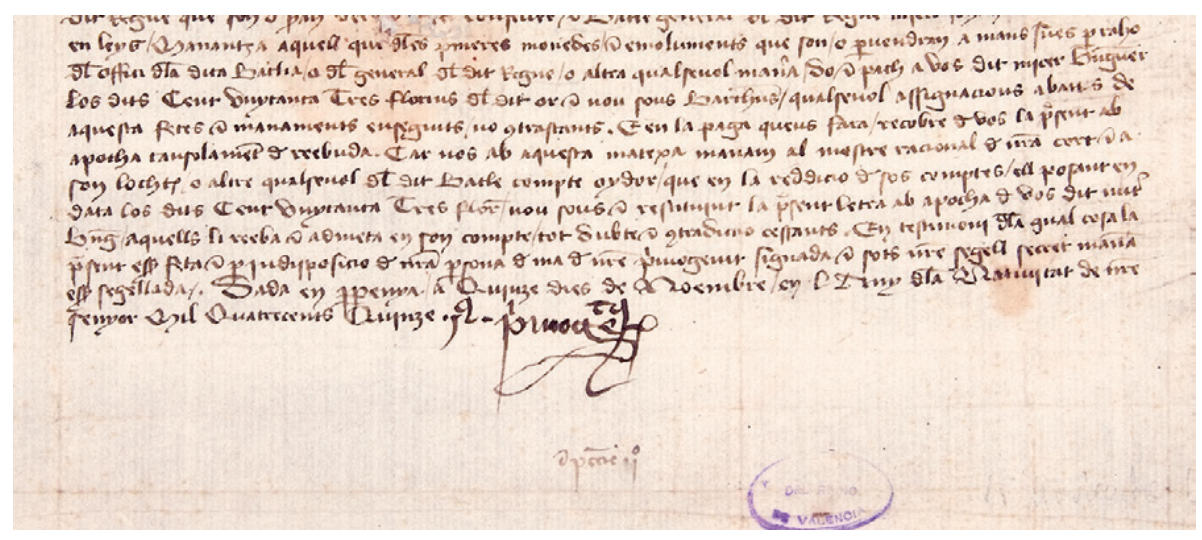

Fig. 1. ARV, Cartas reales Fernando I no 23. Detalle [1415, noviembre 15. Perpiñán].

La firma está presente tanto en las cartas abiertas como en las cerradas y en todo tipo de acciones jurídicas, si bien su grado de ocurrencia es diferente según los casos. Las cifras de la tabla 1 ponen de manifiesto cómo ya durante el reinado de Pedro IV se advierte una mayor presencia de la misma en las cartas cerradas, pauta esta que se confirmará en los reinados sucesivos ${ }^{36}$ y que se debería al hecho de que se destinaban fundamentalmente a asuntos que requerían una mayor privacidad ${ }^{37}$. Por lo que se refiere a las cartas abiertas, la aparición de la suscripción autógrafa resulta desigual, dado que se observa una mayor incidencia de la misma en aquellas cuya acción jurídica conlleva algún reconocimiento por parte del monarca frente al resto, circunstancia que, como veremos seguidamente, responde a la distinta formalidad e intención de unas y otras.

En efecto, en época de Pedro IV se produce la consolidación definitiva de un modelo para las cartas de concesión. Se trata de una carta abierta, redactada en latín y sellada habitualmente con el sello común. En el protocolo, la intitulación, con la expresión completa de los dominios territoriales, va precedida del "Nos" mayestático, la dirección figura en la exposición de motivos o en la disposición y se halla ausente la salutación. En cuanto al texto, además de narración y disposición, encontramos una presencia sistemática de la corroboración, que incrementa la solemnidad de

\footnotetext{
${ }^{36}$ Así lo muestran las cartas recogidas por Rodrigo, Riera 2013 para los reinados de Juan I y Martín I: 92 de las 106 cartas cerradas allí presentes cuentan con la firma del autor de la acción jurídica, mientras que 46 de las 81 cartas abiertas carecen de la misma.

${ }^{37} C f$. Gimeno 2006, p. 89.
} 
la carta al tiempo que refuerza los mecanismos de validación. Por lo que respecta al escatocolo, no se aprecian diferencias en la datación, pero sí en la suscripción, ya que la firma del rey se convertirá en una constante, como prueban las 24 cartas de concesión de Pedro IV conservadas en el ARV, de las que 14 presentan su suscripción autógrafa, mientras sólo 4 de los 23 mandatos que aparecen en forma de carta abierta y redactados en latín cuentan con ella $^{38}$. Esta estructura diplomática guarda muchas similitudes con la de los privilegios menores, que difieren de las cartas en el uso del pergamino y en los elementos de validación, puesto que cuentan con el signum regis y el sello pendiente, así como en la datación, dado que en los privilegios se incluye la referencia al año del reinado, ausente en las cartas ${ }^{39}$. En relación con esta cuestión, es importante apuntar aquí la introducción de la suscripción autógrafa en algunos privilegios ya desde los últimos años del reinado del Ceremonioso $^{40}$.

En las cartas abiertas, la suscripción regia va unida a la colocación de una corona en el astil de la letra $l$ de la palabra Valentiae o València en la intitulación, de acuerdo con una disposición de Pedro IV del año 1377, en la que estipuló que la corona sería trazada de mano del rey ${ }^{41}$. La colección del ARV revela que esta práctica fue escrupulosamente seguida, ya que, para un total de 785 cartas que presentan la firma del monarca, hallamos solamente 13 excepciones, fruto quizá de olvidos involuntarios ${ }^{42}$. Por otra parte, la coloración de la tinta, que en firma y corona es idéntica y suele ser diferente a la del resto de la carta, muestra que, efectivamente, el rey efectuaba el trazado de la corona (véase fig. 2).

\footnotetext{
${ }^{38}$ Constituyen un magnífico ejemplo dos cartas de Pedro IV dadas en Zaragoza el 30 de enero de 1360. Una de ellas es la concesión a la villa de Alpuente de una exención de tributos con motivo de la guerra con Castilla (ARV, C.r. Pedro IV núm. 12), la otra es el mandato al baile general del Reino de Valencia, Pere Boïl, para que ejecute dicha exención (ARV, C.r. Pedro IV núm. 13). Ambos documentos aparecen en forma de carta abierta redactada en latín, sin embargo, están formulados de forma distinta pues la concesión a la villa de Alpuente cuenta con el "Nos" mayestático, la corroboración y la suscripción del rey, elementos de los que carece el mandato al baile general.

${ }^{39}$ Cf. Sevillano 1950, pp. 234-236; Trenchs, Aragó 1983, p. 62.

${ }^{40}$ Por ejemplo, ACA, Canc., Reg. 1429, ff. 184v-185r [1371, abril 30. Valencia]; Reg. 938 , ff. 53v-54v [1381, agosto 24. Zaragoza]; Reg. 944, f. 15r [1384, septiembre 28. Vilafranca del Penedés]; Reg. 948, ff. 13r-14r [1386, agosto 20. Barcelona]. Es también relevante el hecho de que privilegios y cartas se sirven de los mismos tipos gráficos, véanse Aragó 1973, 1982; D’Arienzo 1974a, 1974b; Gimeno 1985, pp. 58-62, 80 y ss.; 1991, pp. 217 y ss.; 2007, pp. 1011 y ss.; Gimeno, Trenchs 1991, pp. 505 y ss.; Oliva, Schena 2012, pp. XXIX-XXXIII.

${ }^{41} \mathrm{Cf}$. Mateu 1977, p. 85.

${ }^{42}$ Así lo sugiere el hecho de que se preparó el astil de la letra " l" manteniendo un trazado simple y con un desarrollo muy marcado, por ejemplo en ARV, C.r. Alfonso V núm. 49 [1418, marzo 22. Valencia]; núm. 51 [1418, abril 27. Valencia] y núm. 53 [1418, mayo 20. Valencia].
} 


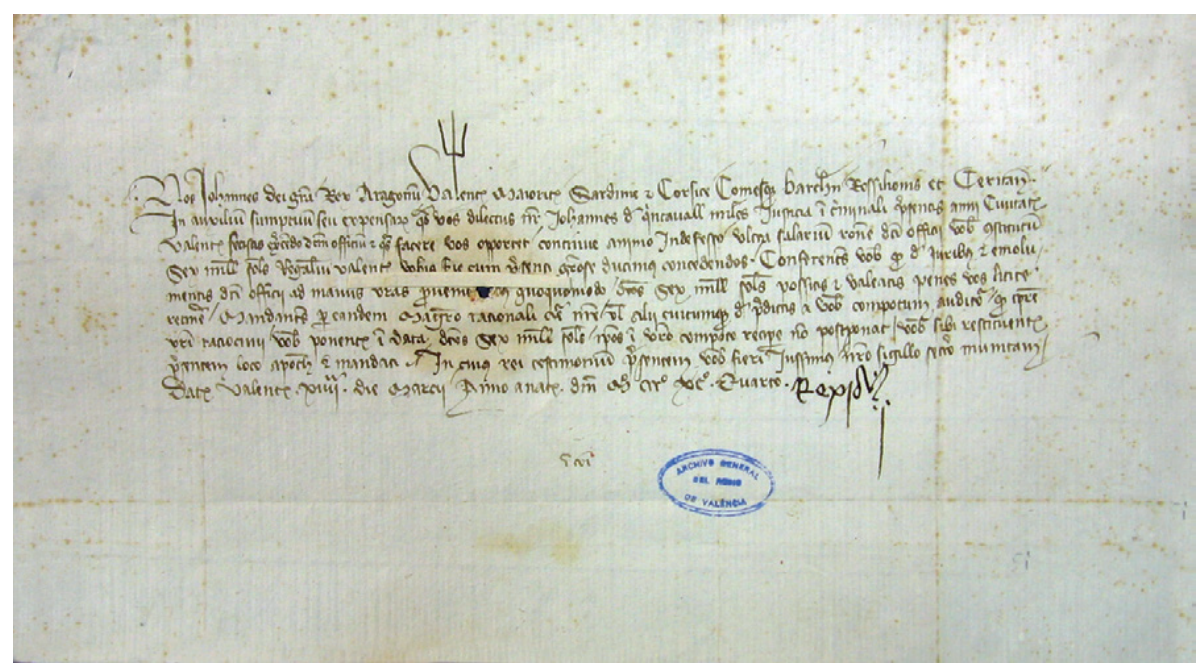

Fig. 2. ARV, Cartas reales Juan I núm. 35 [1394, marzo 14. Valencia].

\subsection{La definición de la carta cerrada y la introducción de las lenguas vulgares}

El segundo fenómeno que comienza a desarrollarse durante el reinado del Ceremonioso es la consolidación de las lenguas romances ${ }^{43}$, muy vinculada al auge de la carta cerrada y a la fijación de una formalidad específica para la misma. La tabla 2 pone de manifiesto cómo la penetración de los vulgares en la carta abierta es un fenómeno lento, mientras la carta cerrada se decanta por ellos de un modo absolutamente preferente ${ }^{44}$.

${ }^{43}$ La colección de Rodrigo, Riera 2013 ofrece una buena muestra del uso del catalán en la Cancillería y, en concreto, en las cartas. Véanse además el apartado dedicado a la lengua cancilleresca y el estudio preliminar; ibídem, vol. I, pp. 13-52 y pp. 53-73 respectivamente.

${ }^{44}$ Confirma estos datos Rubió i Lluch 1908-1921, vol. I, ya que, del total de 122 cartas cerradas de Pedro IV que allí aparecen, 116 fueron escritas en lengua vulgar y 6 en latín (números 139, 141, 208, 255, 364, 371). Del mismo modo, de las 68 cartas abiertas recogidas, 57 fueron escritas en latín y únicamente 11 en lengua vulgar (números 103, 120, 124, 174, 176, 191, 192, $195,217,225)$. 


\begin{tabular}{|c|c|c|c|c|c|}
\hline REINADO & $\begin{array}{c}\text { TOTAL } \\
\text { CARTAS }\end{array}$ & $\begin{array}{c}\text { CARTAS } \\
\text { ABIERTAS } \\
\text { EN LATÍN }\end{array}$ & $\begin{array}{c}\text { CARTAS } \\
\text { ABIERTAS } \\
\text { EN LENGUA } \\
\text { VULGAR }\end{array}$ & $\begin{array}{c}\text { CARTAS } \\
\text { CERRADAS } \\
\text { EN LATÍN }\end{array}$ & $\begin{array}{c}\text { CARTAS } \\
\text { CERRADAS } \\
\text { EN LENGUA } \\
\text { VULGAR }\end{array}$ \\
\hline PEDRO IV & 65 & 58 & 5 & - & 2 \\
\hline JUAN I & 40 & 33 & 3 & - & 4 \\
\hline MARTÍN I & 88 & 77 & 1 & - & 10 \\
\hline FERNANDO I & 34 & 7 & 21 & - & 6 \\
\hline MARÍA & 124 & 54 & 23 & - & 47 \\
\hline ALFONSO V & 676 & 398 & 200 & - & 78 \\
\hline
\end{tabular}

Tabla 2. Selección lingüística de las cartas según sean abiertas o cerradas.

La carta cerrada se definirá, además, por un tenor diplomático propio, caracterizado por una mayor simplicidad en relación con la carta abierta ${ }^{45}$. Desde finales de la década de los 30 , el protocolo se abre con una intitulación breve, gráficamente destacada respecto al cuerpo del documento. En los primeros años se expresó de modos muy diversos, como Rex Petrus ${ }^{46}$, Nos rex Petrus ${ }^{47}$, Petrus, rex Aragonum ${ }^{48}$ o Don Pedro, rey de Aragón ${ }^{49}$, entre otros, si bien en la década siguiente se impondrían las fórmulas Rex Aragonum ${ }^{50}$, Lo Rey o Lo Rey d'Aragó ${ }^{51}$. Este proceso se halla en coincidencia con la progresiva desaparición de la forma De part del rey d'Aragó $\sigma^{52}$ y de la intitulación encabezada con las palabras De $N o s^{53}$, que se hallaban en uso durante los reinados de Jaime $\mathrm{II}^{54}$ y

${ }^{45}$ Cf. Sevillano 1950, p. 209.

${ }^{46}$ ACA, Canc., Reg. 1111, f. 37v [1337, noviembre 18. Calatayud].

${ }^{47}$ ACA, Canc., Reg. 1111, f. 63v [1338, febrero 12. Alzira].

${ }^{48}$ ACA, Canc., Reg. 1112, f. 42r [1339, agosto 14. Barcelona].

${ }^{49}$ ACA, Canc., Reg. 1112, f. 42v [1339, agosto 15. Barcelona].

${ }^{50}$ ACA, Canc., Reg. 1111, f. 62v [1338, febrero 17. Monasterio de la Valldigna].

${ }^{51}$ Existen numerosas variantes, como "Per lo rey d'Aragó"; ACA, Canc., Reg. 1122, f. 63v [1344, octubre 28. Barcelona], $c f$. Rodrigo, Riera 2013, núm. 412, vol. I, p. 467; "Lo Rey d'Aragó e duch d'Athenes e de Neopàtria", utilizada por Pedro IV en 1383, cf. Sevillano 1950, pp. 209-210; o las intitulaciones de Alfonso el Magnánimo: "Lo Rey d'Aragó e de Sicília" y, desde 1445, "Lo Rey d'Aragó e de les dos Sicílies, etc."; AHCG, Ll.r. núm. 507 [1445, julio 4. Castel Nuovo de Nápoles], cf. Arnall, Gironella 2000, vol. II, pp. 778-779.

${ }^{52}$ ACA, Canc., Reg. 1406, f. 7v [1343, abril 3. Barcelona].

${ }^{53}$ ACA, Canc., Reg. 1378, ff. 144v-145v [1343, noviembre 24. Valencia].

${ }^{54}$ Véase Rodrigo, Riera 2013, núms. 114, 146, 147, 158, 159, 165, 176, 185, 187, 188. 
Alfonso IV ${ }^{55}$. Igualmente breve es la dirección, que se limita al nombre del destinatario, su cargo o su condición: En Bernat de Gallach ${ }^{56}$, Batle $^{57}$, Car $\cos ^{58}$; a menudo, incluso -dado que figura completa en el dorso de la carta- se omite, al igual que la salutación. En el texto, narración y disposición suelen formularse de un modo simplificado, ya que, con frecuencia, la carta acompañaba a otros documentos, en los que se realizaban las especificaciones correspondientes, o a órdenes verbales, de modo que actuaba como certificación de la voluntad real y garantía para el destinatario. Prueba de ello son las palabras que la reina María dirigiera al embajador en Castilla Bernat de Gallach: E per tal que $n$ vejats pus clara nostra intenció (...) trametem-vos, dins la present, còpia de les lletres dreçades al dit rey ${ }^{59}$, o su orden al baile general del Reino de Valencia, Berenguer Mercader, para que actuara de acuerdo con las instrucciones contenidas en una scriptura que.us mostrarà En Johan Mercader, mercader d'aquexa ciutat ${ }^{60}$. La datación suele incluir el anuncio del sello ${ }^{61}$-mayoritariamente, el secreto (véase tabla 3)-, probablemente porque servía para cerrar la carta y se rompía al abrirla. Por último, como ya se observaba en la tabla 1, la presencia de la suscripción autógrafa del rey es superior en las cartas cerradas que en las abiertas (véase fig. 3), lo que, como se ha dicho, cabe atribuir a un mayor compromiso del monarca en los asuntos tratados en las primeras, de las que a menudo se afirma que son privadas: Axí per via de memorials e instruccions com per letres privades closes nostres, reza la carta que Alfonso V remitió a los maestres racionales de sus reinos hispánicos el 2 de noviembre de $1447^{62}$.

${ }^{55}$ Véase Rodrigo, Riera 2013, núms. 262, 304, 357, 366, 369, 374. El testimonio más tardío recogido en esta colección es una carta de la reina Leonor del año 1357; cf. ibidem, núm. 518, vol. II, pp. 579-580.

${ }^{56}$ ARV, C.r. María reina núm. 8 [1421, septiembre 4. Barcelona].

${ }^{57}$ ARV, C.r. Juan I núm. 32 [1393, noviembre 28. Amposta].

${ }^{58}$ ARV, C.r. Violant reina núm. 2 [1388, septiembre 15. Zaragoza].

${ }^{59}$ ARV, C.r. María reina núm. 21 [1422, junio 16. Horta].

${ }^{60}$ ARV, C.r. María reina núm. 93 [1441, abril 29. Alcañiz].

${ }^{61}$ Hallamos, no obstante, excepciones, como algunas cartas de la reina María a embajadores dadas entre los años 1421 y 1422, que carecen del anuncio del sello: ARV, C.r. María reina núm. 7 a 15, núm. 19, núm. 22 y núm. 26. Otras, como la carta enviada por Martín el Humano a Ramon Boïl, gobernador del Reino de Valencia, que tampoco presenta anuncio del sello, significativamente, no fue validada con el sello secreto, sino por medio del contrasello con la divisa real de Aragón; ARV, C.r. Martín I s/n (43) [1405, octubre 5. Barcelona]. Para el sello, véase Sagarra 1916-1932, vol. I, núm. 76, pp. 218 y 130. En ocasiones, existe una discrepancia entre el sello anunciado en la carta y el finalmente utilizado, como se advierte, por ejemplo, en dos cartas de Pedro IV: ACA, Canc., Reg. 1168, f. 68 [1359, octubre 15. Cervera] y ACA, Canc., Reg. 1227, f. 42v [1369, mayo 18. San Mateo], en las que se anuncia el sello secreto, pero se apuso el del anillo.

${ }^{62}$ ARV, C.r. Alfonso V núm. 607. 
Esta implicación les llevará a escribir algunas cartas de modo autógrafo o, en su caso, a excusarse por no haberlo hecho, como vemos en los casos de Pedro IV, por ejemplo, en 1355 ante el papa $^{63}$ o en 1374 ante los cónsules de Vilafranca de Conflent ${ }^{64}$, o, más tarde, de la reina María, en sendas cartas dirigidas, tras la muerte de su marido, a su cuñado Juan II y a su sobrino Enrique IV ${ }^{65}$.

\begin{tabular}{|c|c|c|c|}
\hline REINADO & CARTAS & SELLO SECRETO & ANUNCIO DEL SELLO \\
\hline PEDRO IV & 2 & 2 & 2 \\
\hline JUAN I & 4 & 3 & 4 \\
\hline MARTÍN I & 10 & 8 & 8 \\
\hline FERNANDO I & 6 & 6 & 6 \\
\hline MARÍA & 47 & 43 & 22 \\
\hline ALFONSO V & 78 & 73 & 36 \\
\hline TOTAL & 147 & 135 & 79 \\
\hline
\end{tabular}

Tabla 3. Presencia del sello secreto en la carta cerrada.

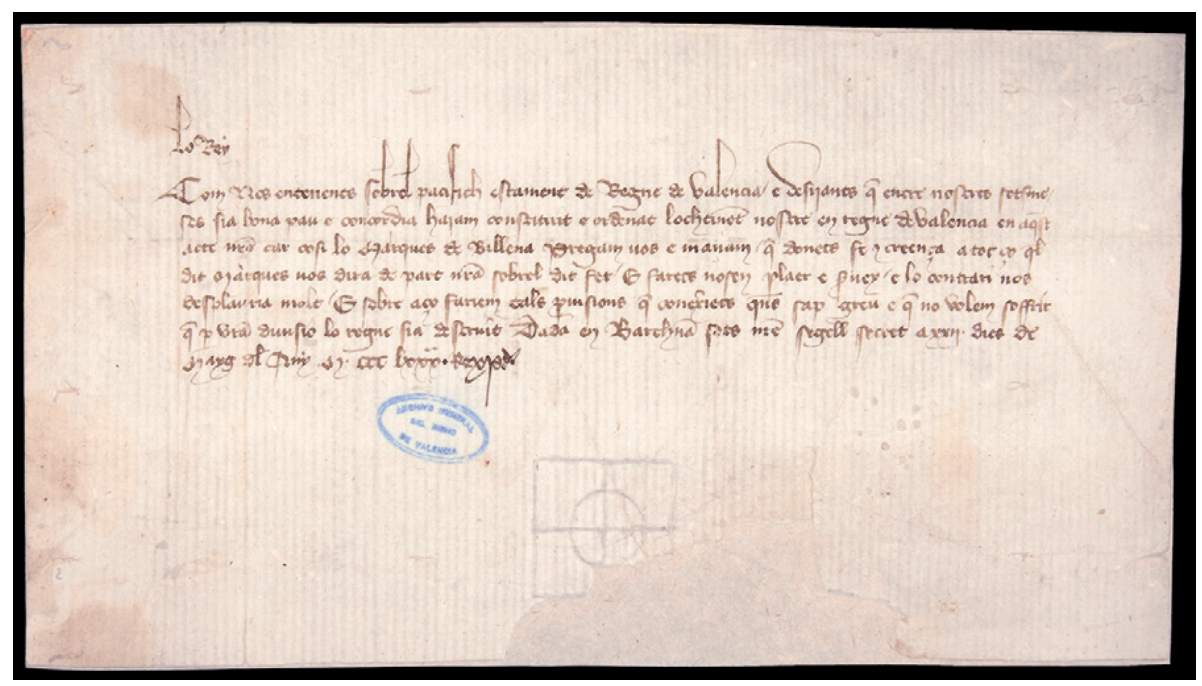

Fig. 3. ARV, Cartas reales, Pedro IV núm. 31 [1380, mayo 22. Barcelona].

\footnotetext{
${ }^{63}$ ACA, Canc., Reg. 1148, f. 5r, cf. Gimeno 2006, p. 100.

${ }^{64}$ ACA, Canc., Reg. 1392, f. 100v, cf. Rodrigo, Riera 2013, núm. 640, vol. II, p. 712.

${ }^{65} C f$. Mandingorra 2014, p. 51.
} 
Una estrecha conexión con esta práctica guardan las anotaciones autógrafas que ocasionalmente se añadían tras la datación, antes o después de la firma. Además de las ya mencionadas de Pedro IV, contamos con diversos testimonios, algunos de ellos originales, de Alfonso $\mathrm{V}^{66}$. Y también en este punto cartas abiertas y cerradas se comportan de modo distinto. Algunas notas en cartas abiertas figuran en mandatos dirigidos al maestre racional: Yo e recebidos estos dineros en mis manos ${ }^{67}$, y constituyen un refuerzo de lo expuesto en el tenor del documento, si bien de un modo neutro, a diferencia de las apostillas presentes en las cartas cerradas, cuyo carácter es mucho más personal ${ }^{68}$ : Esta es mi voluntad ${ }^{69}$, Esta es mi entinción ${ }^{70}$ (véase fig. 4). Es significativo el hecho de que, en estas notas que no forman parte del tenor de la carta, el monarca no utilice el plural mayestático, sino la primera persona del singular, lo que indica una relación más íntima con el destinatario -Ruégote lo fagas escribió el Magnánimo a su esposa ${ }^{71}-$, pero también el ejercicio de una presión más intensa sobre el mismo. Destacan, así, las dirigidas a suplir la ausencia de una redacción autógrafa: Avetla como de mi mano ${ }^{72} \mathrm{o}$, ya en un tono mucho más conminatorio, como en una carta al maestre racional del Reino de Valencia, Guillem de Vich: Avetla como si fuese de mi mano e desto no vos aya más de escrivir ${ }^{73}$.

${ }^{66} C f$. Mandingorra 2008, pp. 175-177. También las hallamos en confirmaciones de privilegios: "Yo he leído la presente e plázeme que así se faga"; ACA, Canc., Reg. 2623, ff. $1 \mathrm{r}-3 \mathrm{r}$ [1455, noviembre 15. Traiecto] y en otros documentos presentes en el mismo registro.

${ }^{67}$ ARV, C.r. Alfonso V núm. 307 [1427, octubre 26. Valencia].

${ }^{68} \mathrm{Cf}$. Mandingorra 2008, p. 172.

${ }^{69}$ ARV, C.r. Alfonso V núm. 652 [1456, agosto 2. Torre Octavia] y núm. 656 [1457, enero 8. Foggia].

${ }^{70}$ ARV, C.r. Alfonso V núm. 169 [1423, febrero 28. Castel Nuovo de Nápoles].

${ }^{71}$ ACA, Canc., Reg. 2546, f. 95v [1451, enero 11. Nápoles]. "Ruego vos de que sea desempachado", añadió en una carta al obispo de Barcelona, dada el 7 de agosto de 1452; ACA, Canc., Reg. 2551, ff. 15v-16r.

${ }^{72}$ ARV, C.r. Alfonso V núm. 658 [1457, enero 18. Foggia].

${ }^{73}$ ARV, C.r. Alfonso V núm. 597 [1446, noviembre 12. Campamento de Presenzano]. 


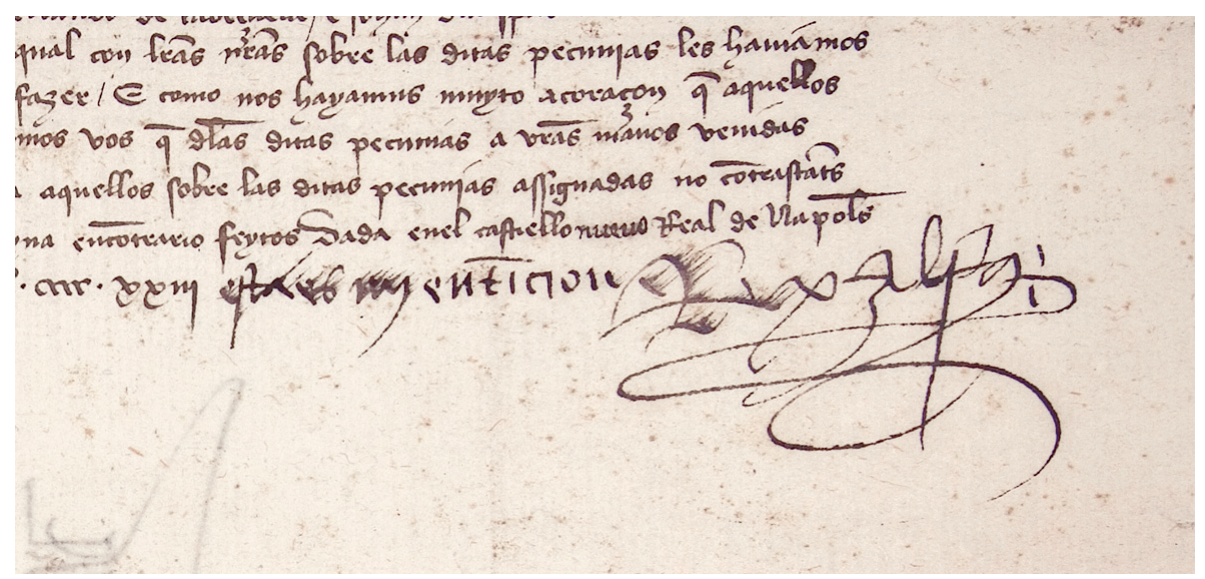

Fig. 4. ARV, Cartas reales Alfonso V n 169. Detalle [1423, febrero 28. Castillo Nuevo de Nápoles].

Paralelamente, entre los últimos años del siglo XIV y los primeros del XV, se consolida la lenta introducción de las lenguas vulgares en la carta abierta, hecho que de nuevo responde tanto a las acciones jurídicas que contiene como a sus destinatarios. Es muestra de ello la fidelidad de las concesiones a la lengua latina ${ }^{74}$, ya que, si bien desde finales del siglo XIV se produce una cierta alternancia lingüística, aún domina el uso del latín. Así lo revelan las 32 cartas de concesión de Martín el Humano conservadas en el $\mathrm{ACA}^{75}$, de las que únicamente 2 se escribieron en lengua vulgar ${ }^{76}$, las 75 concesiones que se custodian en el ARV para el reinado de Alfonso V, entre las que encontramos 10 en vulgar, o las 82 cartas con este contenido jurídico del AHCG, de las que sólo una utiliza el catalán, una carta del infante Juan, dada en $1457^{77}$.

Respecto a la importancia de los destinatarios en la selección lingüística ${ }^{78}$, se pueden señalar algunos hechos relevan-

${ }^{74}$ De hecho, entre los 1000 documentos recogidos por Rodrigo, Riera 2013, que abarcan de 1291 a 1420 y están escritos mayoritariamente en catalán, no hay cartas de concesión.

${ }^{75}$ Véase nota 14.

${ }^{76}$ ACA, Canc., C.r. Martín I núm. 1260 [1409, diciembre 17. Bellesguard] y núm. 1270 [1410, febrero 10. Bellesguard].

${ }^{77}$ AHCG, Ll.r. núm. 579, cf. Arnall, Gironella 2000, vol. II, pp. 856-857.

${ }^{78}$ Véase la rúbrica de las Ordinacions "De la manera de scriure als cardenals", $c f$. Pere el Cerimoniós 2009, p. 186. 
tes $^{79}$, como el uso preferente del castellano en las cartas de Pedro IV al rey de Castilla, Alfonso IV, que se advierte en los registros Guerre Sarracenorum ${ }^{80}$. También es destacable la elección del latín para la redacción de cartas cerradas de Martín I dirigidas al papa ${ }^{81}$ o al rey Ladislao de Hungría $^{82}$. En cuanto al reinado de Alfonso V, vemos que las cartas que envió al arcediano de Niebla, Fernando Díaz de Toledo, persona de su confianza, fueron escritas en latín o en castellano, nunca en catalán ${ }^{83}$. En cambio, las dirigidas a su esposa María se redactaban mayoritariamente en latín o catalán ${ }^{84}$, salvo en algunos casos en los que el delicado carácter de los asuntos tratados probablemente indujo al monarca a servirse del castellano, lengua materna de ambos, con el fin de granjearse su favor ${ }^{85}$.

\subsection{La especialización de la carta cerrada y las variantes en la carta abierta}

Aunque a comienzos del siglo $\mathrm{XV}$ se hallaban definidas tanto la morfología como las funciones de lletres patents y lletres closes, su evolución proseguirá en los años sucesivos con la introducción de variantes conducentes a obtener su mejor adecuación a específicas exigencias comunicativas.

Por una parte, asistimos a una muy precisa definición de las funciones asumidas por la carta cerrada, el canal de comunicación con los embajadores en otros reinos y con los oficiales reales, que se convertiría también en el soporte dominante de agradecimientos y ruegos. Este es el comportamiento que muestran las 23 cartas de la colección del ARV con

\footnotetext{
${ }^{79}$ Es significativa la circunstancia de que, de las 77 cartas reales conservadas en el ACC para el período comprendido entre los reinados de Pedro IV y Fernando I, 70 fueron escritas en latín -69 abiertas y una cerrada- y 7 en catalán -5 abiertas y 2 cerradas-.

${ }^{80}$ ACA, Canc., Reg. 1377 (1339-1341) y 1378 (1341-1349).

${ }^{81}$ ACA, Canc., C.r. Martín I núm. 748 [1405, abril 10. Barcelona] y núm. 769 [1405, mayo 25. Barcelona].

${ }^{82}$ ACA, Canc., C.r. Martín I núm. 1284 [1410, mayo 29. Monasterio de Valldonzella].

${ }^{83}$ Por ejemplo, ARV, C.r. Alfonso V núm. 159 [1423, enero 2. Castel Nuovo de Nápoles]; núm. 161 [1423, enero 25. Castel Nuovo de Nápoles] o núm. 169 [1423, febrero 28. Castel Nuovo de Nápoles].

${ }^{84}$ Así lo muestran, sin ir más lejos, los registros Comune 92 (1450-1451) y 97 (1452-1453), que incluyen 125 cartas dirigidas por Alfonso $\mathrm{V}$ a su esposa, de las que 76 fueron redactadas en latín y el resto en catalán; ACA, Canc., Reg. 2546 y 2551.

${ }^{85}$ Por ejemplo, ARV, C.r. Alfonso V núm. 658 [1457, enero 18. Foggia] y núm. 659 [1457, enero 28. San Severo. Nápoles].
} 
este contenido jurídico, de las que sólo una aparece en forma de carta abierta -la más antigua de todas ellas, una carta de Pedro IV datada en $1380^{86}$, comportamiento que coincide con el que hallamos tanto en el caso de los documentos del ACB -donde los 87 ruegos conservados adoptan la forma de carta cerrada-, como en el AHCG, ya que únicamente 7 de los 84 ruegos allí custodiados se presentan en formato abierto. Con todo, debemos señalar que, en ocasiones, el ruego no se halla tanto en la formulación de la acción jurídica, que puede ser un mandato, como en su contenido, que puede comportar una petición. Así, en 1422, la reina María ordenó al embajador en Castilla, Bernat de Gallach, que le entregara al rey Juan II ciertas cartas y le suplicara que las leyera en su presencia ${ }^{87}$.

Indiscutiblemente, las credenciales y las cartas a los embajadores ${ }^{88}$ se inscriben en ese circuito de comunicación privada que posibilita la carta cerrada y, de hecho, durante el reinado de Alfonso $\mathrm{V}$ presentan dos variantes que resultan notables en la medida en que se vinculan a otros procesos que trataremos seguidamente. La primera es la eliminación del anuncio del sello, especialmente en aquellas cartas que contienen simples instrucciones o encargos, probablemente un ejercicio de simplificación formal en un documento que, cada vez más, trataba de ser ágil y expeditivo. Así mismo, destaca la ausencia de la nota de registro ${ }^{89}$-posibilidad prevista por las Ordinacions ${ }^{90}$ tanto para las cartas autógrafas del monarca, como para las escritas por los secretarios-, hecho que, sin duda, guarda una directa relación con el contenido de las mismas, ya que se detecta también en otros grupos de cartas.

\footnotetext{
${ }^{86}$ ARV, C.r. Pedro IV núm. 32 [1380, noviembre 17. Zaragoza].

${ }^{87}$ ARV, C.r. María reina núm. 23 [1422, agosto 7. Molins de Rei].

${ }^{88}$ Sobre este tema véase Péquignot 2008.

${ }^{89}$ ARV, C.r. Alfonso V núm. 120 [1420, octubre 14. Longobardo] y núm. 460 [1430, septiembre 25. Xàtiva]; ARV, C.r. María reina núm. 10 [1421, noviembre 30. Barcelona]; núm. 19 [1422, junio 30. Sant Cugat]; núm. 23 [1422, agosto 7. Molins de Rei] y núm. 82 [1432, agosto 22. Barcelona]. Carece tanto de nota de registro como de iussio un mandato de Alfonso V al tesorero Mateu Pujades, redactado por el secretario Arnau Fonolleda, que fue validado por medio de la suscripción real y el sello secreto, véase ARV, C.r. Alfonso V s/n [1442, marzo 8. "Camp de Petrofalcone contra Nàpols"]. Sobre el sello, véase Sagarra 1916-1932, vol. I, núm. 96, pp. 223 y 133. Para Arnau Fonolleda, véanse Sevillano 1965, pp. 191-192, 197; Trenchs, Aragó 1983, p. 70.

${ }^{90}$ En la rúbrica "Dels escrivans secretaris"; $c f$. Pere el Cerimoniós 2009, p. 100.
} 


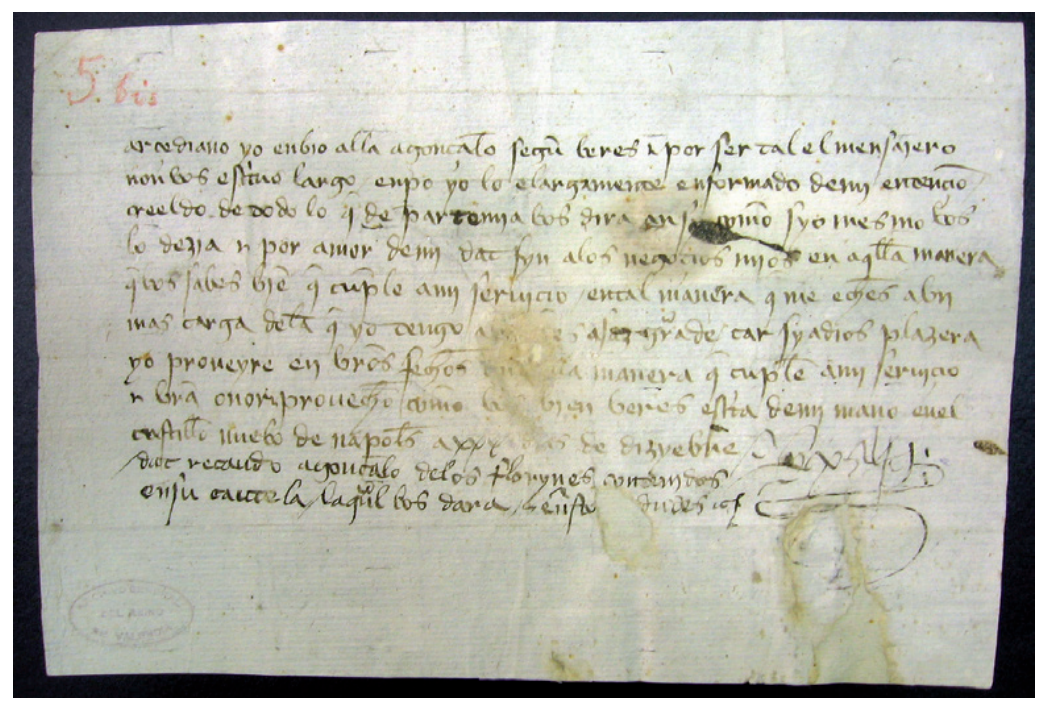

Fig. 5. ARV, Cartas reales Alfonso V núm. 675. Anverso [1422, diciembre 30. Castillo Nuevo de Nápoles].

Por lo que se refiere a las cartas autógrafas, disponemos de las ya conocidas de Pedro IV ${ }^{91}$, así como de cartas de Alfonso V, que resultan de singular interés, no sólo por su carácter hológrafo, sino por el conjunto de sus características extrínsecas e intrínsecas ${ }^{92}$ (véanse figs. 5 y 6). En primer lugar, su tamaño, ya que oscila entre $80 / 120 \times 200 \mathrm{~mm}$, frente a unas dimensiones medias de 95/255 mm x 200/300 mm ${ }^{93}$. En ellas, además, el carácter esquemático de la carta cerrada se acentúa al máximo, hasta el punto de afectar a cláusulas como la datación, que aparece incompleta o es directamente suprimida ${ }^{94}$. En lo que respecta a los elementos de validación, cuentan con la suscripción autógrafa del monarca y con el sello del anillo ${ }^{95}$, colocado en el dorso sobre una estrecha banda de papel, que servía para mantener la carta cerrada hasta su

${ }^{91}$ Véase Gimeno 2006, Apéndice, núms. 1, 2, 4, 5, 6, 7, 8, 12.

${ }^{92}$ Se trata de dos cartas dirigidas al tesorero y al arcediano de Niebla respectivamente: ARV, C.r. Alfonso V núm. 672 [s. d. s. 1.] y núm. 675 [1422, diciembre 30, Castel Nuovo de Nápoles], $c f$. Mandingorra 2008, pp. 173-175. El ACB custodia otra carta autógrafa de Alfonso V, ACB, C.r. núm. 520 [s. d. s. 1.], cf. Oliveras 1946, p. 203 y lámina 1.

${ }^{93}$ Cf. Arnall, Gironella 2000, vol. I, p. 33.

${ }^{94}$ Idénticas características textuales presenta una carta autógrafa dirigida al camarlengo del papa el 6 de abril de 1450; ACA, Canc., Reg. 2697, f. 55v.

${ }^{95}$ En el caso de la carta 672, véase Sagarra 1916-1932, vol. I, núm. 99, pp. 224, 133. Para la carta 675, véase ibidem, vol. I, núm. 100, pp. 224 y 133. 
llegada a destino y sobre la que figura la dirección. Dado que es posible datar una de estas cartas en 1422, es importante señalar que este procedimiento de cierre, diferente al propio de las cartas cerradas, anticipa el de la lletra closa per adreça, cuya aparición era situada durante la lugartenencia del infante Juan, en concreto en el año $1455^{96}$.

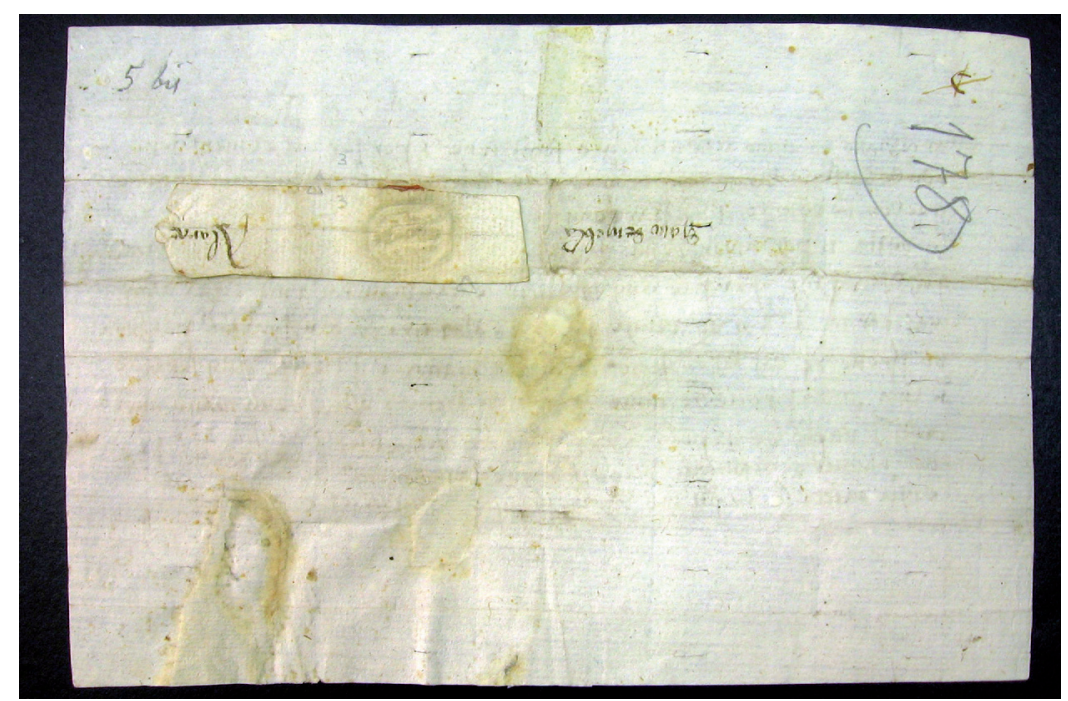

Fig. 6. ARV, Cartas reales Alfonso V núm. 675. Reverso [1422, diciembre 30. Castillo Nuevo de Nápoles].

Entre las cartas carentes de nota de registro hallamos también algunos mandatos que contienen órdenes de pago. Aunque se presentan en formato abierto, su estructura textual es muy simple, con rasgos que hemos señalado como propios de la carta cerrada. Se inician con la intitulación breve Lo Rey, seguida de una dirección igualmente abreviada que da paso directamente a la disposición. Sin duda, sus rasgos más destacables se sitúan en el escatocolo, ya que, mientras en algunos casos cuentan con la suscripción real y el sello secreto, que aparece en la parte central del dorso de la carta ${ }^{97}$, en otros, en cambio, el único elemento de validación es la firma

\footnotetext{
${ }^{96}$ Cf. Arnall, Gironella 2000, vol. I, p. 27.

${ }^{97}$ ARV, C.r. Alfonso V núm. 545 [1441, abril 12. Aversa] y núm. 546 [1441, mayo 25. Campamento de Caiazzo]. También ARV, C.r. Alfonso V núm. 604 [1447, septiembre 9. Campamento del Farfa], aunque, en este caso, fue registrada. Sobre el sello véase Sagarra 1916-1932, vol. I, núm. 96 , pp. 223 y 133.
} 
autógrafa del rey, además, no en su forma habitual, sino abreviada Rex o $\operatorname{Rex} A .{ }^{98}$.

Las versiones simplificadas de la carta abierta se utilizan igualmente para dar soporte a otras acciones jurídicas de naturaleza económica, entre las que destacan las letras de cambio ${ }^{99}$ o los compromisos de pago, como el asumido por Alfonso el Magnánimo de la deuda contraída por su hermano, el infante Pedro, con el mercader florentino Veri de Bardi ${ }^{100}$. Se trata de una carta abierta, escrita en vulgar, en la que el protocolo se reduce a la intitulación breve Lo Rey, sin dirección ni salutación. Sin embargo, presenta una cláusula propia de los documentos más solemnes, la corroboración. Como elementos de validación aparecen la suscripción autógrafa del rey y, a diferencia de las anteriores, el sello del anillo que, además, no se halla en el dorso, sino en el anverso, junto a la firma (véase fig. 7).

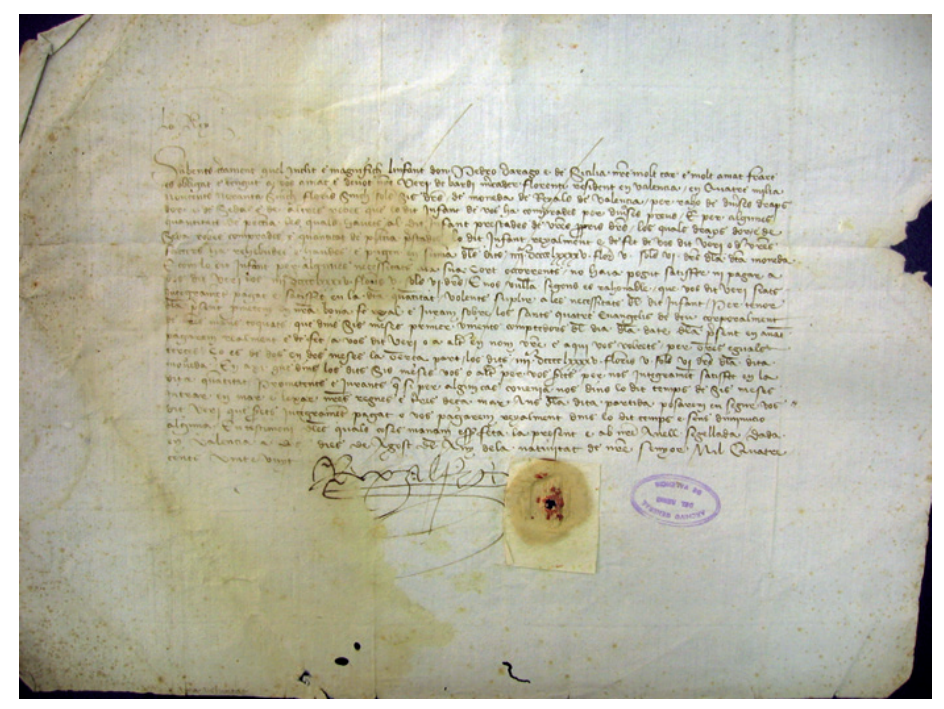

Fig. 7. ARV, Cartas reales Alfonso V núm. 368 [1428, agosto 2. Valencia].

${ }^{98}$ ARV, C.r. Alfonso V núm. 558 [1442, marzo 20. Pozzuoli]; núm. 559 [1442, abril 2. Pozzuoli] y núm. 595 [1446, septiembre 28. Nápoles].

${ }^{99}$ ARV, C.r. María reina núm. 46 [1425, febrero 4. Zaragoza]; núm. 47 [1425, febrero 17. Zaragoza] y núm. 48 [1425, marzo 6. Zaragoza]; ARV, C.r. Alfonso V núm. 522 [1438, marzo 31. Gaeta].

${ }^{100}$ ARV, Cr. Alfonso V núm. 368 [1428, agosto 2. Valencia]. Dos días más tarde, el propio infante Pedro firmaba un reconocimiento de deuda por dicha cantidad con idénticas características formales y sellado con su sello, véase ARV, C.r. infantes núm. 1 [1428, agosto 4. Valencia]. 


\subsection{El triunfo de la suscripción regia y del sello secreto}

Probablemente, el fenómeno más relevante que se produce entre finales del siglo XIV y comienzos del siglo XV es la presencia cada vez mayor de la firma de los monarcas y, sobre todo, su vinculación a un uso creciente del sello secreto y a un proceso de génesis que nace de una orden directa del rey al secretario.

Hemos señalado con anterioridad que el incremento de la suscripción del rey no es lineal, sino que, ya desde el reinado de Pedro el Ceremonioso, se aprecia una superior incidencia de la misma en las cartas cerradas y, dentro de las cartas abiertas, en aquellas que dan soporte a acciones jurídicas que suponen algún tipo de reconocimiento por parte del rey. Así se advierte, por ejemplo, en cartas de concesión de Martín I conservadas en el ACA ${ }^{101}$ o de Fernando de Antequera en el ARV, ya que las únicas que no cuentan con su firma contienen mandatos y no fueron validadas con el sello secreto $^{102}$. Del mismo modo, por lo que se refiere al período de gobierno de Alfonso el Magnánimo, del total de 676 cartas conservadas en el ARV, 8 no presentan su firma autógrafa. De ellas, 7 contienen mandatos que fueron validados con el sello común ${ }^{103}$ y cuya génesis no partió de una orden directa del rey al secretario. Por último, hallamos un comportamiento idéntico en las cartas de la reina María, de las que tan sólo 8 carecen de su suscripción autógrafa, todas ellas mandatos en forma de carta abierta, validados con el sello común ${ }^{104}$. Por su parte, las cifras de la colección del AHCG aún resultan más ilustrativas, ya que 20 de los 68 mandatos en forma de carta abierta allí custodiados para el reinado de Alfonso $\mathrm{V}$ no presentan la suscripción real. En cambio, los 25 ruegos que se conservan para su reinado van firmados por el monarca, sin duda, con el fin de predisponer favorablemente al destinatario y garantizar el éxito de la petición.

\footnotetext{
${ }^{101}$ Sólo una de las 32 concesiones localizadas para los años 1398-1399, 1405 y 1409-1410 no presenta su suscripción autógrafa: ACA, Canc., C.r. Martín I, Caja 02, 127r-v [1398, agosto 26. Zaragoza].

${ }^{102}$ ARV, C.r. Fernando I núm. 10 [1414, diciembre 29. Lérida] y núm. 14 [1414, febrero 8. Zaragoza].

${ }^{103}$ El documento de concesión es: ARV, C.r. Alfonso V núm. 76 [1419, julio 4. Barcelona]. Los mandatos son: ARV, C.r. Alfonso V núm. 49 [1418, marzo 22. Valencia]; núm. 51 [1418, abril 27. Valencia]; núm. 59 [1418, septiembre 25. Monzón]; núm. 91 [1419, septiembre 30. Valencia]; núm. 93 [1419, diciembre 20. Barcelona]; núm. 343 [1428, mayo 27. Valencia] y núm. 345 [1428, junio 3. Valencia].

${ }^{104}$ ARV, C.r. María reina núm. 2 [1421, febrero 26. Tortosa]; núm. 34 [1423, marzo 24. Barcelona]; núm. 38 [1423, septiembre 27. Maella]; núm. 40 [1423, octubre 30. Maella]; núm. 83 [1434, marzo 27. Barcelona]; núm. 84 [1435, mayo 7. Valencia]; núm. 85 [1435, mayo 7. Valencia] y núm. 98 [1442, febrero 17. Zaragoza].
} 
En lo que respecta a los sellos, también hallamos un diferente comportamiento entre cartas abiertas y cerradas, ya que, mientras en la carta abierta domina el uso del sello común ${ }^{105}$, en la cerrada es mayoritaria la utilización del sello secreto, tal como manifiesta la tabla 3. No obstante, esta pauta se modificará paulatinamente, atendiendo tanto a las diferentes acciones jurídicas como a los cambios en la formación de los documentos.

En el caso de las cartas abiertas que contienen concesiones u otras mercedes, la presencia de la corroboración nos informa acerca del sello utilizado, si bien, cuando se trata del sello común no se suele especificar, limitándose a indicar nostro sigillo munitam, aunque puede hacer referencia al sello secreto ${ }^{106}$. Por su parte, en el resto de cartas abiertas cuyo tenor no incluye la corroboración, no se efectúan referencias al sello, salvo cuando se utilizan sellos diferentes al común. A modo de ejemplo, de los 22 mandatos de Martín el Humano conservados en el ARV que adoptan la forma abierta y fueron sellados con el sello común, sólo uno cuenta con el anuncio del sello ${ }^{107}$; en cambio, de los 15 mandatos en igual formato que utilizan otros sellos -14 el secreto y uno el menor- 11 presentan esta fórmula. Por otro lado, del total de 13 mandatos expedidos en forma de carta abierta que conservamos en el ARV para el reinado de Fernando de Antequera que no utilizan el sello común, 12 se sirven del sello secreto y 1 del menor. Finalmente, encontramos algunos casos en los que el anuncio del sello fue escrito a posteriori, tras la datación, por una mano distinta, probablemente porque el sello previsto en inicio era el común, pero finalmente fue sustituido por otro ${ }^{108}$. Del mismo modo, ocasionalmente se dejaba en blanco el espacio correspondiente a la palabra que definía el tipo de sello, que se añadía con posterioridad, una vez se confirmaba cuál sería utilizado $^{109}$. Este comportamiento parece responder a la necesidad de advertir de lo que podría ser considerado una irregularidad en uno de los elementos de validación de la carta, con el fin de garantizar su autenticidad.

No obstante, la relación inicial carta abierta-sello común, carta cerrada-sello secreto no se mantuvo estable durante mucho tiempo, ya que se

\footnotetext{
${ }^{105}$ Por ejemplo, de las 487 cartas abiertas de la colección del AHCG, 364 llevan el sello común, 51 el secreto, 9 el menor, 2 el contrasello y en 61 no se indica el tipo de sello utilizado. Por otra parte, de las 213 cartas cerradas que allí se custodian, 47 llevan el sello secreto y 18 el común, en las restantes no se especifica.

${ }^{106}$ ARV, C.r. Alfonso V núm. 186 [1424 mayo 25. Barcelona].

${ }^{107}$ ARV, C.r. Martín I s/n (41) [1403, mayo 19. Moncada].

${ }^{108}$ ARV, C.r. Pedro IV núm. 36 [1382, junio 12. Alzira]; ARV, C.r. Juan I núm. 4 [1387, abril 12. Barcelona] y núm. 24 [1392, octubre 25. Amposta]; ARV, C.r. Alfonso V núm. 32 [1417, julio 10. Valencia] y núm. 318 [1428, enero 31. Teruel].

${ }^{109}$ ARV, C.r. Alfonso V núm. 139 [1421, junio 22. Mesina]; núm. 202 [1424, agosto 19. Barcelona] y núm. 211 [1424, noviembre 27. Tarragona]; ACV, C.r. 660-050 [1421, noviembre 27. Asedio de Acerra].
} 
observa un progresivo incremento del uso de este último en las cartas abiertas. La tabla 4 muestra cómo el reinado de Martín I marca el punto de inflexión en el dominio del sello común en este tipo de carta y da lugar a un período de utilización creciente del sello secreto -particularmente en aquellas cartas que cuentan con su suscripción autógrafa-, que prosigue en época de Fernando I y alcanza su punto culminante durante el reinado de Alfonso $\mathrm{V}$, en especial entre los años 1425 y 1447 -en gran medida en coincidencia con las campañas de Nápoles-, en el que únicamente 12 de las 358 cartas abiertas conservadas en el ARV para este período no utilizaron el sello secreto ${ }^{110}$.

\begin{tabular}{|c|c|c|c|c|c|c|}
\hline REINADO & CARTAS & $\begin{array}{c}\text { SELLO } \\
\text { COMÚN }\end{array}$ & $\begin{array}{c}\text { SELLO } \\
\text { SECRETO }\end{array}$ & $\begin{array}{c}\text { SELLO } \\
\text { MENOR }\end{array}$ & CONTRASELLO & OTROS \\
\hline PEDRO IV & 63 & 44 & 17 & - & - & 2 \\
\hline JUAN I & 36 & 20 & 15 & - & - & 1 \\
\hline MARTÍN I & 78 & 35 & 40 & 2 & - & 1 \\
\hline FERNANDO I & 28 & 9 & 17 & 1 & - & 1 \\
\hline MARÍA & 75 & 15 & 46 & - & 2 & 12 \\
\hline ALFONSO V & 598 & 56 & 518 & 5 & - & 19 \\
\hline
\end{tabular}

Tabla 4. Presencia del sello en la carta abierta.

En todo caso, la presencia creciente en las cartas abiertas del sello secreto en detrimento del sello común, se relaciona directamente con la suscripción autógrafa de los monarcas y con un proceso de génesis que parte de una orden del rey a uno de los secretarios. El triunfo de este procedimiento debe atribuirse en primer lugar a su mayor rapidez y agilidad, imprescindibles en momentos en los que el volumen de la documentación se incrementa enormemente en consonancia con la creciente complejidad de la realidad política. Ciertamente, no se puede afirmar que tras el uso de estas formas hubiese una voluntad decidida del monarca de ocultar información relativa a sus acciones de gobierno, aunque podrían estar:

destinées a répondre aux besoins d'une administration de plus en plus compliquée. Ces nouveaux actes ont pour principal caractère de devenir peu à peu les instruments de la volonté personnelle du roi, les organes per lesquels en dehors des actes soumis à la «vérification» des cours souveraines s'exercera son pouvoir absolu ${ }^{111}$.

\footnotetext{
11010 se sirvieron del sello común y 2 del sello denominado por Sagarra simplemente como "sigillum regium", véase Sagarra 1916-1932, vol. I, núm. 98, pp. 224 y 133.

${ }^{111}$ Cf. Giry 1894, p. 765.
} 
En principio, parecería evidente que las circunstancias del reinado de Alfonso el Magnánimo, con largos períodos de regencia ${ }^{112}$, favorecieron el recurso a mecanismos que, en ocasiones, iban en detrimento de la solemnidad de los documentos. De hecho, desde finales de 1448, tras la instalación de la corte en Nápoles, se detecta una inversión en la tendencia, con una recuperación del proceso de expedición documental a través de la Cancillería ${ }^{113}$ y una vuelta al uso del sello común para la validación de las cartas abiertas ${ }^{114}$. Es más, las cartas abiertas de su esposa, la reina María, presentan un comportamiento idéntico, con un uso creciente del sello secreto hasta 1447, momento en que se rompe esta tónica y nos encontramos con cartas validadas con el contrasello ${ }^{115}$, los sellos de la segunda lugartenencia ${ }^{116}$ o el sello mayor ${ }^{117}$.

\section{CONCLUSIÓN}

Hemos visto cómo, partiendo de un modelo unitario, la carta real diplomática de la Corona de Aragón, a lo largo de la segunda mitad del siglo XIV y las primeras décadas del XV, supo adaptarse a las diferentes acciones jurídicas a las que debía dar soporte, a la diversa condición de sus destinatarios y a las nuevas necesidades comunicativas de la creciente autoridad real, a través de su forma de expedición, de estudiadas combinaciones de características internas y externas y de una cuidadosa selección lingüística.

De este modo, la monarquía pudo dotarse de unos instrumentos de gobierno y comunicación ágiles, adecuados a su condición itinerante, a unos

\footnotetext{
${ }_{112}$ Para una visión general del reinado de Alfonso V sigue constituyendo una referencia Ryder 1987, 1992.

${ }^{113}$ Así lo muestra el hecho de que la mayor parte de las cartas de los registros del ACA 2456 (Comune 92, 1450-1451), 2551 (Comune 97, 1452-1453) y 2622 Curie 22 (1455-1458), son fruto de órdenes del rey al ya protonotario Arnau Fonolleda, si bien el papel de los secretarios en la producción de la carta sigue siendo fundamental, como se ve en el registro 2623 (Diversorum 15, 1455-1458), en el que la iussio se dirige en gran medida a Francesc Martorell y Mateu Joan. Para Martorell, véase Sevillano 1965, p. 197.

${ }^{114}$ De las 37 cartas abiertas que conservamos en el ARV para los últimos años del reinado del Magnánimo, 24 fueron validadas con el sello común y 13 con el secreto.

${ }^{115}$ ARV, C.r. María reina núm. 110 [1447, noviembre 1. Barcelona] y núm. 117 [1455, noviembre 12. Barcelona]. Para el sello véase Sagarra 1916-1932, vol. I, núm. 167, pp. 237 y 142.

${ }^{116}$ ARV, C.r. María reina núm. 111 [1449, junio 4. Perpiñán]; núm. 112 [1449, septiembre 1. Perpiñán]; núm. 113 [1451, marzo 18. Barcelona]. Sobre el sello véase Sagarra 1916-1932, vol. I, núm. 168, p. 237.

${ }^{117}$ ARV, C.r. María reina núm. 114 [1451, julio 21. Barcelona]; núm. 115 [1451, agosto 3. Barcelona] y núm. 116 [1451, noviembre 4. Barcelona]. Se trata de reconocimientos de deuda, todos ellos en forma de carta abierta, redactados en latín y firmados por la reina, a los que el uso del sello mayor confería un grado más de solemnidad. Para el sello véase Sagarra 1916-1932, vol. I, núm. 84, pp. 220 y 132.
} 
territorios geográficamente dispersos y a una gestión cada vez más compleja, sin que por ello dejaran de constituir vehículos al servicio del poder y de la majestad real. Unos instrumentos, en suma, que anticipan prácticas de escritura del futuro Estado moderno, ese estado que, en palabras de Maravall, se gobierna desde un despacho ${ }^{118}$ y genera unas inmensas exigencias comunicativas en todos los órdenes: la economía, la diplomacia, la guerra e, incluso, los requerimientos de los súbditos ${ }^{119}$. Tal vez por ello, consciente de la importancia que asumía la transmisión de la información, Alfonso V ordenó a su tesorero Mateu Pujades remitir por duplicado ciertas cartas para Jordi d'Ornós, obispo de Vic ${ }^{120}$ :

L'altre dia, vos trametem per lo feel scrivà nostre N'Andreu Gaçull un plech de cartes dreçades al Cardenal de Vich, les quals havem aprés fetes duplicar e-us trametem de present en un altre plech. Per ço, us pregam e manam stretament que los dits dos plechs trametau per diverses vies, a fi que si la un se perdrà, haja l'altre ${ }^{121}$.

\section{BIBLIOGRAFÍA CITADA}

Aragó Cabañas, Antonio María (1973), La escribanía de Juan I, en VIII Congreso de Historia de la Corona de Aragón. II. La Corona de Aragón en el siglo XIV, Valencia, Artes gráficas, vol. I, pp. 269-293.

Aragó Cabañas, Antonio María (1982), Prenotaciones a la escritura cancilleresca de Alfonso el Magnánimo, en IX Congresso di Storia della Corona d'Aragona. La Corona d'Aragona e il Mediterraneo: aspetti e problemi comuni da Alfonso il Magnanimo a Ferdinando il Cattolico (1416-1516), Nápoles, Società Napoletana di Storia Patria, vol. II, pp. 49-55.

Aragó Cabañas, Antonio María; Trenchs Òdena, José (1979), Notas para una tipología documental de Jaime I, en X Congreso de Historia de la Corona de Aragón. Jaime I y su época, Zaragoza, Institución Fernando el Católico, vol. III, pp. 353-361.

Arxiu del Regne de València (2000), Guía del Archivo del Reino de Valencia, Valencia, Generalitat Valenciana.

\footnotetext{
${ }^{118}$ Cf. Maravall 1986, vol. II, p. 477.

${ }^{119} \mathrm{Cf}$. Maravall 1986, vol. I, p. 148.

${ }^{120}$ Jordi d'Ornós, obispo de Vic desde el 4 de junio de 1423; $c f$. Eubel 1913, vol. I, p. 526.

${ }^{121}$ ARV, C.r. Alfonso V núm. 549 [1441, junio 23. Campamento del Covante].
} 
Arnall Juan, Maria Josepa; Gironella i Delgà, Anna (2000), Lletres reials a la ciutat de Girona (1293-1515). Estudi i edició crítica a cura de M. Josepa Arnall i Juan, Anna Gironella i Delga, Barcelona, Fundació Noguera - Ajuntament de Girona, 4 vols.

Canellas López, Ángel; Trenchs Òdena, José (1988), Cancillería y cultura. La cultura de los escribanos y notarios de la Corona de Aragón (13441479), Zaragoza, Institución Fernando el Católico.

Casula, Francesco Cesare (1967), La cancelleria di Alfonso III il Benigno, re d'Aragona (1327-1336), Padua, CEDAM.

Casula, Francesco Cesare (1970), Carte reali diplomatiche di Alfonso III il Benigno, re d'Aragona, riguardanti l'Italia, Padua, CEDAM.

Casula, Francesco Cesare (1973), Il documento regio nella Sardegna Aragonese, Padua, CEDAM.

Casula, Francesco Cesare (1977), Carte reali diplomatiche di Giovanni I il Cacciatore, re d'Aragona, riguardanti l'Italia, Padua, CEDAM.

Casula, Francesco Cesare (1979), Observaciones paleográficas y diplomáticas sobre la cancillería de Jaime I el Conquistador, en X Congreso de Historia de la Corona de Aragón. Jaime I y su época, Zaragoza, Institución Fernando el Católico, vol. III, pp. 435-451.

Collura, Paolo (1983), La cancelleria dei re aragonesi in Sicilia, Palermo, Scuola Grafica Salesiana.

Conde y Delgado de Molina, Rafael; Cárcel Ortí, María Milagros (1996), Corona de Aragón: documentación real. Tipología (s. XIII-XIV), en Marques, José (coord.), Diplomatique royale du Moyen Âge, XIII-XIV siècles. Actes du Colloque, Porto, Faculdade de Letras da Universidade do Oporto, pp. 273-288.

D’Arienzo, Luisa (1970), Carte reali diplomatiche di Pietro IV il Cerimonioso, re d'Aragona, riguardanti l'Italia, Padua, CEDAM.

D'Arienzo, Luisa (1974a), Gli scrivani della Cancelleria aragonesa all'epoca di Pietro il Cerimonioso (1336-1387), en Casula, Francesco Cesare; D’Arienzo, Luisa (coords.), Studi di Paleografia e Diplomatica, Padua, CEDAM, pp. 137-198.

D’Arienzo, Luisa (1974b), Alcune considerazioni sul passaggio dalla scrittura gotica all'umanistica nella produzione documentaria catalana dei secoli XIV e XV, en Casula, Francesco Cesare; D’Arienzo, Luisa (coords.), Studi di Paleografia e Diplomatica, Padua, CEDAM, pp. 199-227.

D'Arienzo, Luisa (1981), La cancelleria di Pietro IV nell'asedio di Alghero del 1354, "Archivio Storico Sardo" 32, pp. 139-158.

Eubel, Conrad (1913), Hierarchia catholica Medii Aevi sive Summorum Pontificum, SRE Cardinalium, Ecclesiarum Series ab anno 1198 usque 
ad annum 1431 perducta, vol. I, Münster, Sumptibus et Typis Librariae Regensbergianae.

Finke, Heinrich (1908-1922), Acta Aragonensia. Quellen zur deutschen, italienischen, französischen, spanischen, zur Kirchen- und Kulturgeschichte aus der diplomatischen Korrespondenz Jaymes II. (12911327), 3 vols., Berlin - Leipzig, Dr. Walther Rothschild.

Gimeno Blay, Francisco (1985), La escritura gótica en el País Valenciano después de la conquista cristiana del siglo XIII, Valencia, Universitat de València.

Gimeno Blay, Francisco (1991), A propósito del manuscrito vulgar del Trescientos. El ms. K.I.6 de El Escorial y la minúscula cursiva libraria de la Corona de Aragón, "Scrittura e Civiltà" 15, pp. 205-245.

Gimeno Blay, Francisco (1999), "Missivas, mensageras, familiares". Instrumentos de comunicación y de gobierno en la España del 500, en Castillo, Antonio (comp.), Escribir y leer en el siglo de Cervantes, Barcelona, Gedisa, pp. 193-209.

Gimeno Blay, Francisco (2006), Escribir, reinar. La experiencia gráfico-textual de Pedro IV el Ceremonioso (1336-1387), Madrid, Adaba.

Gimeno Blay, Francisco (2007), De la "luxurians littera" a la "castigata et clara". Del orden gráfico medieval al humanístico (siglos XV-XVI), "Litterae caelestes" 2 /1, pp. 9-51.

Gimeno Blay, Francisco; Trenchs Òdena, José (1991), La escritura medieval de la Corona de Aragón (1137-1474), "Anuario de Estudios Medievales" 21, pp. 493-511.

Giry, Arthur (1894), Manuel de Diplomatique. Diplômes et chartes. Chronologie technique. Éléments critiques et parties constitutives de la teneur des chartes. Les chancelleries. Les actes privés, París, Hachette.

Gubern, Ramon (1955), Epistolari de Pere III, Barcelona, Els Nostres Clàssics.

Mandingorra Llavata, María Luz (2008), "Avetla como de mi mano”. Autógrafos de Alfonso el Magnánimo en el Archivo del Reino de Valencia, "Boletín de la Sociedad Castellonense de Cultura" 84, pp. 167-178.

Mandingorra Llavata, María Luz (2014), Entre dos reinos. Cartas de María de Castilla, reina de Aragón, "Ars Longa” 23, pp. 41-58.

Maravall, José Antonio (1986), Estado moderno y mentalidad social (siglos $X V$ a XVII), 2 vols., Madrid, Alianza.

Mateu y Llopis, Felipe (1977), El "Rex Valentiae" en los diplomas, sellos y monedas, en Cicle de conferències commemoratives del VII cè centenari de Jaume I. Cronistes Oficials del Regne de València, Valencia, Cronistes del Regne de València, pp. 75-91. 
Murphy, James J. (1986), La retórica en la Edad Media. Historia de la retórica desde San Agustín hasta el Renacimiento, México, Fondo de Cultura Económica. [1 ${ }^{\mathrm{a}}$ ed. en inglés: Rethoric in the Middle Ages. A History of Rethorical Theory from St. Augustine to the Renaissance, Berkeley, University of California Press, 1974].

Oliva, Anna Maria; Schena, Olivetta (2012), Lettere regie alla città di Cagliari. Le carte reali dell'Archivio comunale di Cagliari, vol. I, 13581415. A cura di Anna Maria Oliva, Olivetta Schena, Roma, Istituto Storico Italiano.

Olivar, Marçal (1936), Notes entorn a la influència del 'Ars dictandi' en la prosa catalana de la cancelleria a finals del segle XIV. El ms. Y-129-7 de la Biblioteca Colombina, "Estudis universitaris catalans” 22 (núm. especial: Homenatge a Antoni Rubió i Lluch), pp. 631-635.

Oliveras Caminal, José (1946), Archivo Capitular de la Santa Iglesia Catedral de Barcelona. Cartas Reales (siglos XII-XV). Catálogo, Barcelona, Imp. Altés.

Péquignot, Stéphane (2008), Les instructions aux ambassadeurs des rois d'Aragon (XIII ${ }^{-}-X V^{e}$ siècles). Jalons pour l'histoire de la fabrique d'une parole royale efficace, "Cahiers de linguistique hispanique médiévale" 31, pp. 17-43.

Péquignot, Stéphane (2009), Au nom du roi. Pratique diplomatique et pouvoir dans le règne de Jacques II d'Aragon (1291-1327), Madrid, Casa de Velázquez.

Pere el Cerimoniós (1983), Crònica, en Les quatre grans cròniques. Jaume I, Bernat Desclot, Ramon Muntaner, Pere III. Revisió del text, pròlegs i notes per Ferran Soldevila, Barcelona, Biblioteca Selecta, pp. 1001-1225.

Pere el Cerimoniós (2009), Ordinacions de la Casa i Cort. Transcripció, edició i notes del manuscrit de València a cura de Francisco $M$. Gimeno Blay, Daniel Gozalbo Gimeno i José Trenchs Òdena (†). Introducció per Francisco M. Gimeno Blay, Valencia, Universitat de València.

Perelman, Les (1991), The Medieval Art of Letter Writing. Rethoric as institutional expression, en Bazerman, Charles; Paradis, James (eds.), Textual Dynamics of the Professions. Historical and Contemporary Studies of Writing in Professional Communities, Madison, Wisconsin, University of Wisconsin Press [Edited for digital presentation by Nicole Ashton and Heidi Scott, 2004].

Petrucci, Armando (1963), Diplomatica vecchia e nuova, "Studi Medievali" 3/4, pp. 785-798. 
Rockinger, Ludwig (1863-1864), Briefsteller und Formelbücher des elften bis vierzehnten Jahrhunderts, Múnich, Franz [Reimpr. Múnich, Scientia Verlag, 1969].

Rodrigo Lizondo, Mateu; Riera i Sans, Jaume (2013), Col-lecció documental de la Cancelleria de la Corona d'Aragó. Textos en llengua catalana (1291-1420), 2 vols, Valencia, Universitat de València.

Rubió i Balaguer, Jordi (1990), Influència de la sintaxi llatina en la cancelleria catalana del segle $X V$, en Rubió i Balaguer, Jordi, Humanisme $i$ Renaixement, Barcelona, Publicacions de l'Abadia de Montserrat, pp. 296-304.

Rubió i Lluch, Antoni (1908-1921), Documents per a la història de la cultura catalana mig·eval, 2 vols., Barcelona, Institut d'Estudis Catalans, [Reimpr. Barcelona, Institut d'Estudis Catalans, 2000].

Ruiz Calonja, Joan (1956), El valor literario de los preámbulos de la cancillería catalano-aragonesa del siglo $X V$, "Boletín de la Real Academia de Buenas Letras de Barcelona" 26, pp. 205-234.

Ryder, Alan (1987), El reino de Nápoles en la época de Alfonso el Magnánimo, Valencia, Alfons el Magnànim. [ $1^{\mathrm{a}}$ ed. en inglés: The Kingdom of Naples under Alfonso the Magnanimous: the making of a modern state, Oxford, Clarendon Press, 1976].

Ryder, Alan (1992), Alfonso el Magnánimo rey de Aragón, Nápoles y Sicilia, 1396-1458, Valencia, Alfons el Magnànim. [1 $1^{\mathrm{a}}$ ed. en inglés: Alfonso the Magnanimous: King of Aragon, Naples and Sicily, 1396-1458, Oxford, Clarendon Press, 1990].

Sagarra i Siscar, Ferran de (1916-1932), Sigil-lografia catalana. Inventari, descripció $i$ estudi dels segells de Catalunya, 4 vols., Barcelona, Estampa Arts Gràfiques Suc. d'Henrich i Ca. Institució Patxot.

Sánchez Cutillas, Carmelina (1967), Lletres closes de Pere el Cerimoniós endreçades al Consell de València, Barcelona, Rafael Dalmau.

Sevillano Colom, Francisco (1950), Apuntes para el estudio de la cancillería de Pedro el Ceremonioso, "Anuario de Historia del Derecho Español" 20, pp. 137-241.

Sevillano Colom, Francisco (1965), Cancillerías de Fernando I de Antequera y de Alfonso Vel Magnánimo, "Anuario de Historia del Derecho Español” 36, pp. 169-216.

Sevillano Colom, Francisco (1968), De la cancillería de la Corona de Aragón, en Martínez Ferrando, archivero. Miscelánea de estudios dedicados a su memoria, Madrid, ANABAD, pp. 1-30.

Trenchs Òdena, José (1991), Casa, corte y cancillería de Pedro el Grande (1276-1285), Roma, Bulzoni Editore. 
Trenchs Òdena, José; Aragó Cabañas, Antonio María (1983), Las Cancillerías de la Corona de Aragón y Mallorca desde Jaime I a la muerte de Juan II, Zaragoza, Institución Fernando el Católico.

Vincke, Johannes (1936), Documenta selecta: mutuas civitatis Arago-Cathalaunicae et ecclesiae relationes illustrantia, prolegomenis ac notis instructa edidit Iohannes Vincke, Barcelona, Biblioteca Balmes.

Fecha de recepción del artículo: abril 2015

Fecha de aceptación y versión final: diciembre 2016 